Longo et al., Afr. J. Infect. Dis. (2016) 10 (1): 29 - 31

http://dx.doi.org/10.4314/ajid.v10i1.6

\title{
ATYPICAL EXTENSIVE GENITAL ULCER IN FULL BLOWN AIDS WITH SLIM DISEASE
}

\section{Jean De Dieu Longo ${ }^{1}$, Aida Rasacanu ${ }^{2}$, François-Xavier Mbopi-Kéou ${ }^{3}$, Gérard Grésenguet ${ }^{1}$, Laurent Bélec $^{2}$,*}

${ }^{1}$ Centre National de Référence des Maladies Sexuellement Transmissibles et de la Thérapie Antirétrovirale, and Unité de Recherches et d'Intervention sur les Maladies Sexuellement Transmissibles et le SIDA, Département de Santé Publique, Faculté des Sciences de la Santé de Bangui, Bangui, Central African Republic ; ${ }^{2}$ Laboratoire de Microbiologie, Hôpital

Européen Georges Pompidou, Assistance Publique-Hôpitaux de Paris, and Faculté de Médecine Paris Descartes,

Université Paris Descartes (Paris V), Sorbonne Paris Cité, Paris, ${ }^{3}$ Faculty of Medicine \& Biomedical Sciences, Department of Microbiology and Infectious Diseases, University of Yaounde I and Ministry of Public Health, Yaounde, Cameroon.

E-mail: laurent.belec@egp.aphp.fr

\begin{abstract}
Background: Atypical and exceptional clinical presentation of full blown AIDS may be observed in sub-Saharan Africa. We report herein the case of a Central African 37-year-old male patient presented with full blown AIDS, a typical picture of slim disease with marked cachexia and wasting faces. In addition, the patient was suffering from very extensive genital ulcer with complete loss of substance of the genitalia.

Methods: Extensive histological and microbiological analysis of the genital lesion was carried out.

Results: HIV-1 serology was positive, the HIV-1 RNA plasma viral load was $5.3 \log$ copies/ml and CD4 T cell count was 1 per $\mu \mathrm{L}$. Search for Mycobacterium tuberculosis in sputum and urine was negative by direct microscopic examination with Ziehl-Neelsen staining. Testing for syphilis serology was negative. Direct immunofluorescence detection on genital ulcer scraping was negative for Chlamydia trachomatis and Treponema pallidum. Furthermore, the infections with Haemophilus ducreyi and Chlamydia trachomatis were excluded by PCR on genital swabs.Genital PCR was positive for herpes simplex virus (HSV) type 2. Marked improvement was observed within 6 weeks after starting empirical therapy including first-line antiretroviral therapy, cotrimoxazole, doxycycline and valacyclovir, with progressive healing of genital ulcer and negativity of HSV PCR. Conclusion: Taken together, the extensive genital ulcer in this patient is likely the result of a multifactorial process, involving both profound cellular immune depression and complex genital infectious process in which herpetic infection may have participated as a chronic worsening co-factor.
\end{abstract}

Key words: Slim disease, HIV, Extensive genital ulcer, Herpes simplex virus type 2.

\section{Introduction}

Atypical and exceptional clinical presentation of full blown AIDS may be observed in sub-Saharan Africa. We herein report the case of a patient suffering from slim disease associated with quasi disappearance of the genitalia in which empirical large spectrum anti-infectious treatment, consisting of first line antiretroviral regimen, cotrimoxazole, doxicycline and valacyclovir, allowed improvement in the general condition as well as the extensive genital ulcer.

\section{Case Presentation}

A 37-year-old heterosexual man living in the Central African Republic suffered from major chronic fatigue and wasting for more than 24 months (figure 1-A), and moderately painful, extensive ulcer with important loss of substance of the perineum and genitalia for 11 months (Figure 1). HIV-1 serology was positive, the HIV-1 RNA plasma viral load was $5.3 \log$ copies/ml and CD4 T cell count was 1 per $\mu \mathrm{L}$.

Search for Mycobacterium tuberculosis in sputum and urine was negative by direct microscopic examination with Ziehl-Neelsen staining. Testing for syphilis serology was negative. Direct immunofluorescence detection on genital ulcer scraping was negative for Chlamydia trachomatis and Treponema pallidum. Furthermore, the infections with Haemophilus ducreyi and Chlamydia trachomatis were excluded by PCR on genital swabs. The histopathological examination of the genital biopsies showed inflammation and few multinucleated giants cells, without any evidence of neoplasia, amoebiasis, Donovan bodies nor mycotic infection. Only the real-time PCR for herpes simplex virus hominis (HSV) on genital swabs was repeatedly positive and analysis of resulting melting curves revealed HSV type 2 (HSV-2) infections.

Treatment with first-line antiretroviral therapy (triple combination with zidovudine, lamividine and efavirenz), cotrimoxazole (sulfamethoxazole $800 \mathrm{mg}+$ trimethoprime $160 \mathrm{mg}$; once daily), doxycycline $(100 \mathrm{mg}$ twice daily) and valacyclovir $(1 \mathrm{~g}$ three-times daily) was initiated. His condition improved remarkably within 6 weeks of anti-infectious treatment with weight gain $(+16 \mathrm{~kg})$, immune-restoration with CD4 at 139 per $\mu \mathrm{L}$. Also, progressive healing of genital ulcer could be observed with negativity of HSV PCR. Finally, he was loss-to-followed up 3 months after treatment initiation. 


\section{Longo et al., Afr. J. Infect. Dis. (2016) 10 (1): 29 - 31 \\ http://dx.doi.org/10.4314/aiid.v10i1.6}

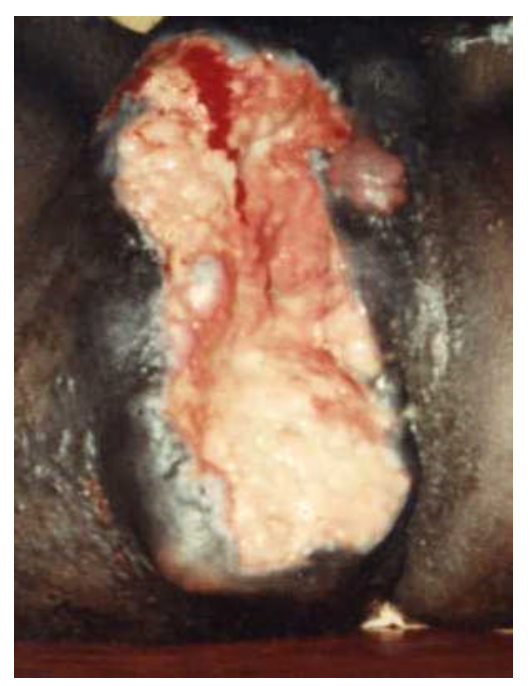

Figure 1: AIDS patient suffering from "slim disease" with typical wasting with loss of substance of the genitalia

\section{Discussion}

Our patient was suffering from the typical so-called "slim disease". Slim disease associated with HIV infection was first reported in Uganda by Serwadda et al. (1985). This condition corresponds to the "HIV wasting syndrome" (Belec et al., 1992, WHO, 1998), which constitutes a typical indicator of full blown AIDS in sub-Saharan Africa (Mhiri et al., 1992). Our patient presented with a particular brightness of look associated with the melting of Bichat balls on cheekbones face, resembling a simian face. Such clinical presentation is a common picture occurring during the overproduction of pro-inflammatory cytokines, which characterizes the HIV wasting syndrome in Africa (Belec et al., 1994; Belec et al., 1995, TeviBenissan et al, 1997). Tuberculosis representing the principal differential diagnosis of HIV wasting syndrome in Central Africa (Colebunders et al., 1987; Belec et al., 1992; Mbopi-Keou et al., 1992) was formally excluded. Lastly, the patient's general condition rapidly improved under antiretroviral therapy without anti-tuberculosis treatment.

Our patient suffered also from spectacular extensive genital ulcer resulting in almost complete loss of the genitalia. We have first looked for possible infectious causes of genital ulcer lesions depending on local epidemiology, including Treponema pallidum (O'Farrell et al., 1994), Haemophilus ducreyi (Quale et al., 1990; Mohammed and Ulumide, 2008), Chlamydia trachomatis (Read and McNulty, 2013), and genital herpetic infection (Gupta et al., 2007; Corey and Wald, 2008). Furthermore, we checked for uncommon causes of genital ulcers, including neoplasia, amoebiasis, donovanosis and mycotic infection (Cohen and Mayer, 2007; Workowski and Berman, 2010; Roett et al., 2012). All were negative. Finally, only HSV-2 genital herpetic infection was found repeatedly positive by PCR, indicating at least genital shedding of herpes DNA. However, the histopathological examination on genital biopsies showed only inflammation and few multinucleated giant cells, without typical intra-nuclear inclusions, characteristic for active herpetic infection. (Rigopoulos et al, 2008). Thus, it is difficult to attribute the etiology of this extensive genital ulcer with complete loss of substance of the genitalia solely to genital herpetic infection. However, it is well established that HIV-1 and HSV-2 are synergistic co-pathogens (Chatoufi et al., 2012). Therefore, persistent opportunistic HSV-2 infection in the context of full AIDS may likely be a cofactor of extensive genital ulcer in this patient. Empirical anti-infectious treatment contributed to the improvement in the patient's general condition and healing of genital ulcer. This observation clearly confirms at posteriori the potent role of cellular immune depression as the main trigger favoring extensive genital ulcer in HIV-1 infected patient, as classically reported (Heng et al., 1994; Hutchinson et al., 1994; Sparling et al., 2001; Palamaras et al., 2006; Gupta et al., 2007).

Taken together, the etiology of this unusual genital ulcer is likely secondary to the combination of immunosuppression and infectious genital process in which herpetic infection may have participated as chronic worsening cofactor. It is well-recognized that the differential diagnosis of genital ulcerations is challenging, especially in the immunocompromised persons (Sparling et al., 2001). Once a diagnosis is made, therapeutic modalities can be equally difficult. Controlling circulating HIV-1 RNA load and CD4 cell counts may have a drastic contributory effect on the clinical improvement of such lesions. Indeed, it is often difficult to ascertain whether clinical improvement of genital ulcerations is due to an effective antiretroviral treatment regimen, the use of concomitant anti-infectious therapeutic modalities, or both.

Finally, our observation is reminiscent of the multifactorial approach of infectious diseases in tropical biotopes, also known as the "tropical pathogenic complex", concept defined by the geographer Maximillien Sorre (Sorre, 1933). This concept characterizes the simultaneous occurrence of different pathogens in a determined area, their host reservoir, their transmission modes and susceptible individuals.

Authors' Contribution: The authors participated fully in the conception, development, and creation of this paper. AR and LB made the virological diagnosis. All authors participated to the writing of the paper and approved the final version of the manuscript. Informed consent was obtained from the patient.

Competing interests: The authors declare that they have no conflict of interests. 
Longo et al., Afr. J. Infect. Dis. (2016) 10 (1): 29 - 31

\section{http://dx.doi.org/10.4314/ajid.v10i1.6}

\section{References}

1. Bélec L., Mhiri C., Di Costanzo B., and Gherardi R (1992). The HIV wasting syndrome. Muscle and Nerve, 15: 856-857.

2. Bélec L., Meillet D., Hernvann A., Grésenguet G., and Gherardi R (1994). Differential elevation of circulating interleukin-1 beta, tumor necrosis factor alpha, and interleukin-6 in AIDS-associated cachectic states. Clin Diagnostics Lab Immunol, 1: 117-120.

3. Bélec L., Meillet D., Grésenguet G., and Gherardi R.K (1995). Increased tumor necrosis factor-alpha serum levels in patients with HIV wasting syndrome and euthyroid sick syndrome. J Acquir Immune Deficiency Syndr and Human Retrovirol, 8: 212-214.

4. Belec L., Mbopi Keou F.X., Cancre N, Gresenguet G., and Georges A.J (1992). The WHO/Bangui clinical case definition of AIDS in Black Africa. Status of 1986-1991. Annales de Médecine Interne (Paris), 143: 204-213.

5. Chentoufi A.A., Dervillez X., Rubbo P.A., Kuo T., Zhang X., Nagot N., Tuaillon E., Van De Perre P., Nesburn A.B., and Benmohamed L (2012). Current trends in negative immuno-synergy between two sexually transmitted infectious viruses: HIV-1 and HSV-1/2. Current Trends in Immunology, 13: 51-68.

6. Cohen D.E., and Mayer K. Genital ulcer disease. In: J.D. Klausner, and E.W. Hook III, editors. Current Diagnosis \& Treatment of Sexually Transmitted Diseases. New York, NY: McGraw-Hill Medical; pp.19-26, 2007.

7. Colebunders R, Mann J.M., Francis H., Bila K., Izaley L., Kakonde N., Kabasele K., Ifoto L., Nzilambi N., and Quinn T.C (1987). Evaluation of a clinical case-definition of acquired immunodeficiency syndrome in Africa. The Lancet, 8531: 492-494.

8. Corey L, and Wald A (2008). Genital herpes. In: K.K. Holmes, P.F. Sparling, W.E. Stamm, P. Piot, J.W. Wasserheit, and L. Corey, editors. Sexually transmitted diseases, 4th ed. New York: McGraw Hill; pp. 399-437.

9. Gupta R., Warren T., and Wald A (2007). Genital herpes. The Lancet, 370: 2127-2137.

10. Heng M.C., Heng S.Y., and Allen S.G (1994). Co-infection and synergy of human immunodeficiency virus-1 and herpes simplex virus-1. The Lancet, 343: 255-258.

11. Hutchinson C.M., Hook 3rd E.W., Shepherd M., Verley J., and Rompalo A.M (1994). Altered clinical presentation of early syphilis in patients with HIV infection. Ann Intern Med. 121: 94-100.

12. Mbopi-Keou F.X., Bélec L., Esunge P.M., Cancre N., and Gresenguet G (1992). World Health Organization clinical case definition for AIDS in Africa: an analysis of evaluations. East Afr Med J, 69: 550-553.

13. Mhiri C, Bélec L., Di Costanzo B., Georges A., and Gherardi R (1992). The slim disease in African patients with AIDS. Trans Royal Soc Trop Med Hyg, 86: 303-306.

14. Mohammed T.T. and Olumide Y.M (2008). Chancroid and human immunodeficiency virus infection--a review. Intern J Dermatol, 47:1-8.

15. O'Farrell N., Hoosen A.A., Coetzee K.D., and van den Ende J. (1994). Genital ulcer disease: accuracy of clinical diagnosis and strategies to improve control in Durban, South Africa. Genitourinary Medicine, 70: 7-11.

16. Palamaras I., Richardson D., Healy V., Lyons D., Byrne M., and Lamba H (2006). An atypical herpetic vulval ulcer in an African woman: an important lesson. Int J STD AIDS, 17:427-428.

17. Quale J., Teplitz E., and Augenbraun M (1990). Atypical presentation of chancroid in a patient infected with the human immunodeficiency virus. American Journal of Medicine, 88: 43N-44N.

18. Read P.J, and McNulty A (2013). Lymphogranuloma venereum presenting as genital ulceration and inguinal syndrome. Med J Aust, $199: 27-28$.

19. Rigopoulos D., Malouchou K., Alevizos A., Larios G., Papadogiorgak H., Lima K., and Antoniou C. (2008). Extensive atypical genital herpes simplex type 2 infection as an initial manifestation of acquired immune deficiency syndrome. Acta Dermatovenerologica Croatica, 16: 145-148.

20. Roett M.A., Mayor M.T., and Uduhiri K.A (2012). Diagnosis and management of genital ulcers. American Family Physician, 85: $254-262$.

21. Serwadda D., Mugerwa R.D., Sewankambo N.K., Lwegaba A., Carswell J.W., Kirya G.B., Bayley A.C., Downing R.G., Tedder R.S., and Clayden S.A(1985). Slim disease: a new disease in Uganda and its association with HTLV-III infection. The Lancet, 8460: 849-852.

22. Sorre M (1933). Complexes pathogènes et géographie médicale. Annales de Géographie, 235 : 1-18.

23. Sparling J.D., Norwood C.W., Turiansky G.W., and Oster C.N (2001). Diagnostic and therapeutic dilemmas of a large scrotal lesion in an AIDS patient. AIDS Reader, 11: 43-47.

24. Tevi-Benissan C., Di Costanzo B., Gresenguet G., and Belec L (1997). Overproduction of tumor necrosis factor-alpha in African patients with HIV-1 infection, cachexia and low tri-iodothyronine syndrome. Médecine Tropicale (Marseille), 57: 349-352.

25. Workowski K.A., and Berman S (2010). Centers for Disease Control and Prevention. Sexually transmitted diseases treatment guidelines, 2010". Morbidity and Mortality Weekly Report (MMWR) Recommendations and Reports, 59: 1-110.

26. World Health Organization (1998). Acquired immunodeficiency syndrome (AIDS); 1987 revision of CDC/WHO case definition for AIDS. Weekly Epidemiol Record, 63: 1-8. 